\title{
Severe Short Stature in Two Siblings as the Presenting Sign of ACP5 Deficiency
}

\author{
Christiaan de Bruin $^{\mathrm{a}} \quad$ Zerrin Orbak $^{\mathrm{b}}$ Melissa Andrew ${ }^{\mathrm{a}}$ Vivian Hwa $^{\mathrm{a}}$ \\ Andrew Dauber ${ }^{\mathrm{a}}$ \\ ${ }^{a}$ Cincinnati Center for Growth Disorders, Division of Endocrinology, Cincinnati Children's Hospital Medical Center, \\ Cincinnati, Ohio, USA; ${ }^{b}$ Department of Pediatric Endocrinology, Faculty of Medicine, Ataturk University, \\ Erzurum, Turkey
}

\section{Established Facts}

- ACP5 mutations are known to cause spondyloenchondrodysplasia.

\section{Novel Insights}

- ACP5 deficiency can present as isolated, severe short stature in the absence of any of the autoimmune and neurological abnormalities commonly found in spondyloenchondrodysplasia.

- ACP5 deficiency should be considered as a rare cause of severe, proportionate short stature.

\section{Key Words}

ACP5 deficiency $\cdot$ Spondyloenchondrodysplasia $\cdot$ Short stature $\cdot$ Skeletal dysplasia $\cdot$ Exome sequencing

\begin{abstract}
Background: $A C P 5$ deficiency is known to cause spondyloenchondrodysplasia (SPENCD), which is characterized by various autoimmune and neurological symptoms in addition to short stature. Methods: Two siblings from a consanguineous Turkish family, a girl aged 13 years (P1) and a boy aged 8 years (P2), presented to their endocrinologist with progressive growth failure and severe short stature ( -5 SDS). They had no comorbid conditions and, on physical examination, there were no signs of an overt skeletal dysplasia with normal appearance of extremities. Other than a low baseline IGF-1, extensive laboratory workup, including growth hor-
\end{abstract}

\section{KARGER}

E-Mail karger@karger.com

www.karger.com/hrp mone stimulation and IGF-1 generation tests, was normal. Exome sequencing was performed. Results: Exome sequencing identified the presence of a homozygous frameshift mutation (p.Ser258Trpfs*39) in ACP5 in both siblings, which was confirmed by Sanger sequencing. This specific mutation has previously been described in patients with SPENCD. Additional workup in the two siblings showed distinct features of skeletal dysplasia on X-rays consistent with SPENCD, but none of the common autoimmune or neurological abnormalities associated with this condition. Conclusion: Severe short stature can be the only presenting sign of $A C P 5$ deficiency and the latter could therefore be considered as a rare cause in the differential diagnosis of severe, proportionate growth failure.

(c) 2016 S. Karger AG, Basel (c) 2016 S. Karger AG, Basel

$1663-2818 / 16 / 0855-0358 \$ 39.50 / 0$
Andrew Dauber, MD, MMSc

Division of Endocrinology, Cincinnati Children's Hospital Medical Center

3333 Burnet Avenue, MLC 7012

Cincinnati, OH 45229 (USA)

E-Mail Andrew.dauber@cchmc.org 


\section{Introduction}

Short stature can be caused by many different diseases and conditions, as well as by primary growth disorders affecting growth plate physiology, GH/IGF-1 axis signaling, cell cycle control, and centriole functions. In cases of severe idiopathic short stature, whole exome sequencing can be used for diagnostic purposes with a reasonable chance of identifying the underlying genetic defect [1]. In this study, exome sequencing led to the identification of a homozygous mutation in ACP5 in two siblings who presented with isolated extreme short stature but without the typical autoimmune features seen in the rare form of spondyloenchondrodysplasia (SPENCD) caused by ACP5 mutations.

\section{Case Report}

A 13-year-old girl (P1) and her 8-year-old brother (P2) from a consanguineous Turkish family presented to their pediatric endocrinologist for the evaluation of severe short stature (approx. -5 SDS). Both children were born full term after uncomplicated pregnancies and deliveries. The exact birth weight of P1 was unknown; P2 had a birth weight of 3,000 g. The neonatal course and overall health during infancy and childhood had been excellent for both siblings other than the onset of progressive postnatal growth failure with a gradual decline in height to below -5 SDS. Neither of the siblings had a history of frequent childhood infections, recurrent fevers, skin or joint problems, or chronic gastrointestinal complaints, and their weight relative to their height had been normal throughout their childhood. The neurological review of symptoms was negative, other than a slight delay in the onset of walking (2 years of age) in both siblings. School performance was noted to be moderate in both of them. The father's height was $153 \mathrm{~cm}(-3.2$ SDS) and the mother's height was $150 \mathrm{~cm}(-1.7$ SDS), which translated into a female mid-parental height of $145 \mathrm{~cm}(-2.5 \mathrm{SDS}$, for P1) and a male mid-parental height of $158 \mathrm{~cm}$ (-2.5 SDS, for P2). The parents are second-degree cousins and both were asymptomatic, with no significant past medical history. The parents have 2 other healthy children: a 15-year-old female with a height of 151 $\mathrm{cm}(-1.4$ SDS) and an 11-year-old male with a height of $126 \mathrm{~cm}$ $(-2.7$ SD). The timing of puberty had been appropriate for age in both parents and the 15-year-old sister.

On physical examination, it was noted that both children had severe short stature $(\mathrm{P} 1$ : height $123 \mathrm{~cm},-5.5 \mathrm{SD}$; $\mathrm{P} 2$ : height $98 \mathrm{~cm}$, $-5.1 \mathrm{SD})$ with a mild decrease in the sitting height ratio in $\mathrm{P} 1$ and a normal ratio in P2 (P1: 0.50, -2.5 SD; P2: 0.54, -0.5 SD [2]), no facial dysmorphisms without any midline defects and normal hands and nails. BMI and head circumference were normal for their age (table 1). Cognitive and verbal skills were also appropriate for their age. There were no joint or skin abnormalities, and neurological examination including gait was normal. The endocrine workup was normal, except for low baseline IGF-1 levels in both siblings and a low IGFBP-3 level in P2. However, a clonidine-levodopa growth hormone stimulation test and an IGF-1 generation test were normal in both siblings (table 1).
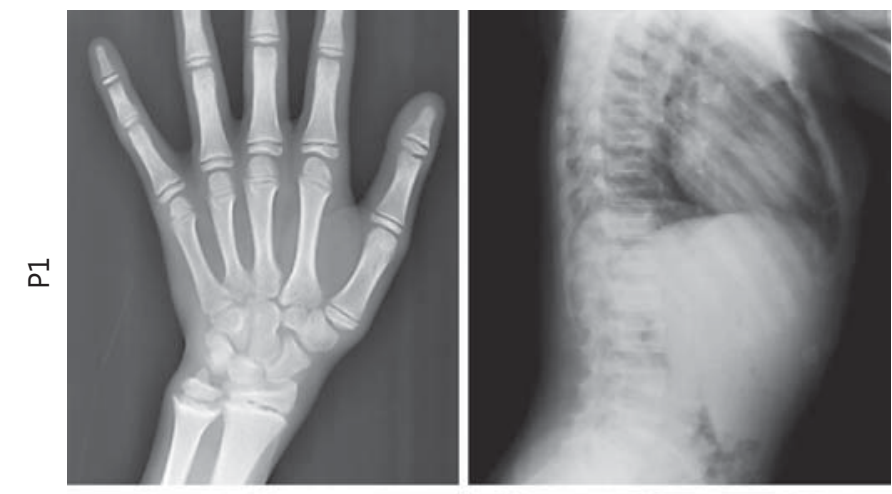

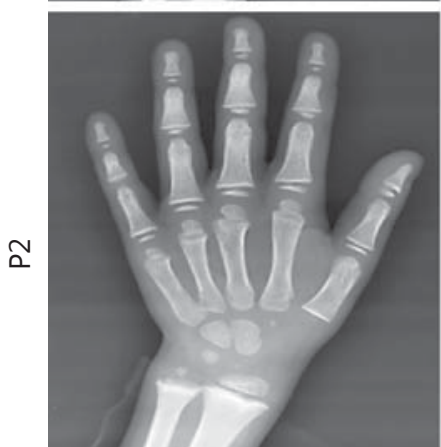

Right hand

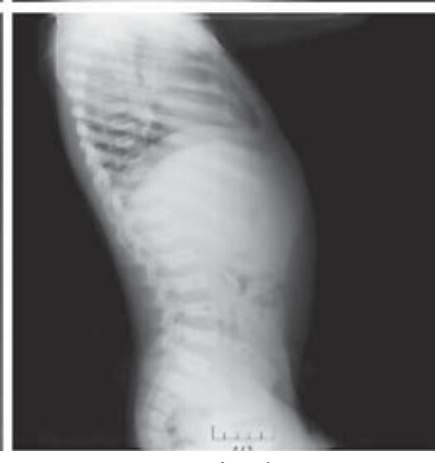

Lateral spine
Fig. 1. Conventional radiographs as part of the skeletal survey in $\mathrm{P} 1$ and P2. On X-rays of the right hand, one can see a widening of the epiphyses of the ulna and radius in both siblings with cupping of the ulna and dense thickening of the radioulnar ligament without the presence of a Madelung deformity. The lateral spine film shows flattening of the vertebral bodies (platyspondyly).

Written informed consent for research testing was obtained for all family members. Whole exome sequencing of the two affected siblings was performed at Cincinnati Children's Hospital Medical Center as previously described [3]. Given the consanguinity of the parents and the severity of the growth phenotype, we filtered the exome data looking for nonsynonymous, homozygous variants present in both siblings with a minor allele frequency of $<0.001$ in the 1,000 Genomes and ExAC Browser databases (http://browser.1000genomes.org/, http://exac.broadinstitute.org/). This identified 10 different candidate genes (online suppl. table 1; see www.karger.com/doi/10.1159/000443684 for all online suppl. material), only one of which (ACP5) harbored a previously reported, pathogenic homozygous frameshift mutation (p.Ser258Trpfs*39) associated with severe growth failure [4]. The other 9 candidate genes had no apparent connections to any known growth disorders or biological pathways affecting human growth. Sanger sequencing confirmed the presence of the homozygous p.Ser258Trpfs*39 mutation in both siblings. Mutations in the ACP5 gene are known to cause SPENCD, characterized by short stature due to skeletal dysplasia in addition to various autoimmune and neurological abnormalities [4, 5]. Subsequent to our exome analysis, we performed skeletal surveys on both siblings, which revealed characteristic findings of 
Table 1. Anthropometric and laboratory data

\begin{tabular}{|c|c|c|c|}
\hline & Reference range & $\mathrm{P} 1$ & $\mathrm{P} 2$ \\
\hline \multicolumn{4}{|l|}{ Initial workup } \\
\hline Age, years & & 13 & 8 \\
\hline Height, cm & & 123 & 98 \\
\hline Height SDS & & -5.5 & -5.1 \\
\hline Sitting height/height & & 0.50 & 0.54 \\
\hline Sitting height/height SDS & & -2.5 & -0.5 \\
\hline Weight, kg & & 25 & 14 \\
\hline BMI & & 16.5 & 14.6 \\
\hline BMI SDS & & -0.9 & -0.8 \\
\hline Head circumference, $\mathrm{cm}$ & & 52 & 51 \\
\hline Head circumference SDS & & -1.3 & -1.2 \\
\hline Hemoglobin, g/dl & $11.5-14.0$ & 12.4 & 12.0 \\
\hline Leukocytes, $1,000 / \mathrm{mm}^{3}$ & $4.5-13.5$ & 5.6 & 8.1 \\
\hline Thrombocytes, $1,000 / \mathrm{mm}^{3}$ & $150-450$ & 290 & 260 \\
\hline Sedimentation rate, $\mathrm{mm} / \mathrm{h}$ & $5-20$ & 22 & 25 \\
\hline Creatinine, $\mathrm{mg} / \mathrm{dl}$ & $0.3-0.7$ & 0.4 & 0.4 \\
\hline Urinalysis & & normal & normal \\
\hline Free T4, ng/dl & $0.8-2.2$ & 1.2 & 1.08 \\
\hline $\mathrm{TSH}, \mathrm{mcIU} / \mathrm{ml}$ & $0.6-5.5$ & 1.05 & 4.73 \\
\hline IGF-1, ng/ml & $\begin{array}{r}13 \text { y: } 192-640 \\
8 \text { y: } 113-261\end{array}$ & 104 & $<25$ \\
\hline IGFBP-3, ng/ml & $\begin{array}{r}13 \text { y: } 2.1-6.2 \\
8 \text { y: } 2.1-4.2\end{array}$ & 4.04 & 1.75 \\
\hline GH peak stimulation, $\mathrm{ng} / \mathrm{ml}$ & $>10$ & 23.9 & 11.4 \\
\hline IGF-1 gene test (pre>post), ng/ml & & $140>267$ & $25>62$ \\
\hline \multicolumn{4}{|c|}{ Additional workup (after exome sequencing) } \\
\hline Anti-ds DNA, U/ml & $0-20$ & 0 & 0 \\
\hline ANA & & negative & negative \\
\hline C3, g/l & $0.9-1.8$ & 1.03 & 0.99 \\
\hline $\mathrm{C} 4, \mathrm{~g} / \mathrm{l}$ & $0.1-0.4$ & 0.19 & 0.22 \\
\hline $\operatorname{IgA}, g / 1$ & $\begin{array}{r}13 \text { y: } 0.9-4.65 \\
8 \text { y: } 0.7-3.0\end{array}$ & 1.6 & 2.9 \\
\hline $\operatorname{IgG}, \mathrm{g} / \mathrm{l}$ & $\begin{array}{r}13 \text { y: } 9.1-19.6 \\
8 \text { y: } 7.6-21.3\end{array}$ & 19.2 & 14.5 \\
\hline IgM, g/l & $\begin{array}{r}13 \text { y: } 0.8-2.8 \\
8 \text { y: } 0.7-3.8\end{array}$ & 1.17 & 0.90 \\
\hline $\mathrm{CK}, \mathrm{U} / \mathrm{l}$ & $<190$ & 189 & 182 \\
\hline Coombs & & negative & negative \\
\hline Reticulocytes, \% & $1-2$ & 1.5 & 1.5 \\
\hline Bilirubin, mg/dl & $<1.2$ & 0.18 & 0.25 \\
\hline $\mathrm{LDH}, \mathrm{U} / \mathrm{l}$ & $120-330$ & 214 & 272 \\
\hline Skeletal survey & & $\begin{array}{l}\text { figure } 1 \\
\text { (right hand) }\end{array}$ & $\begin{array}{l}\text { figure } 1 \\
\text { (lateral spine) }\end{array}$ \\
\hline MRI brain & & normal & normal \\
\hline
\end{tabular}

SPENCD with flattening of the vertebral bodies (platyspondyly), widening of the epiphyses of the upper and lower distal extremities (fibula/tibia/ulna/radius), cupping of the ulna and dense thickening of the radioulnar ligament without the presence of a Madelung deformity (fig. 1). Additional laboratory and radiological evaluation demonstrated no evidence of subclinical autoimmune or neurological dysfunction (table 1).

\section{Discussion}

The ACP5 gene encodes the tartrate-resistant acid phosphatase (TRAP), a protein thought to play a major role in immune regulation and bone physiology. TRAP deficiency was first described in 1976 in a report of two brothers with severe platyspondyly [6]. TRAP-deficient 
Table 2. Overview of the clinical characteristics of P1, P2 and the SPENCD patients described in the studies by Briggs et al. [4] and Lausch et al. [5]

\begin{tabular}{lllll}
\hline Parameter & P1 & P2 & Briggs $(\mathrm{n}=10)$ & Lausch $(\mathrm{n}=14)$ \\
\hline Age & 13 & 8 & 7 & 3 \\
Height SDS (range) & -5.4 & -5.1 & $-3.4(-1$ to -6.5$)$ & $-2.7(-1.8$ to -4.2$)$ \\
Thrombocytopenia & no & no & $5 / 10$ & $5 / 13$ \\
Hemolytic anemia & no & no & $2 / 10$ & $2 / 13$ \\
Leukopenia & no & no & n.a. & $4 / 13$ \\
Hypothyroidism & no & no & $3 / 10$ & $1 / 13$ \\
Elevated anti-DNA or anti-ANA titers & no & no & $8 / 10$ & $6 / 13$ \\
Lupus-like symptoms (ACR) & no & no & $4 / 10$ & $6 / 13$ \\
Lupus nephritis & no & no & $3 / 10$ & $3 / 13$ \\
Spasticity & no & no & $4 / 10$ & $4 / 13$ \\
Developmental delays & minimal ${ }^{1}$ & minimal ${ }^{1}$ & $2 / 10$ & $4 / 13$ \\
Intracranial calcifications & no & no & $4 / 6$ & $6 / 13$ \\
\hline
\end{tabular}

Median age is depicted for the study population in the studies by Briggs et al. [4] and Lausch et al. [5]. Proportions are depicted for the patients in the studies by Briggs et al. [4] and Lausch et al. [5] on whom detailed clinical information was reported in the supplementary methods of both papers. n.a. $=$ Not assessed; ACR $=$ according to American College of Rheumatology criteria.

${ }^{1}$ Slight delay in the start of walking (around age 2 years); otherwise unremarkable neurodevelopment.

mice have metaphyseal changes with increased bone density and immunological impairments including impaired dendritic function $[7,8]$.

The ACP5 mutation identified in our two siblings (p.Ser258Trpfs*39) was previously reported as one of a number of ACP5 mutations that cause SPENCD [4]. A concurrent study by Lausch et al. [5] independently confirmed the causality of ACP5 mutations in this syndrome, which is characterized by a mild skeletal dysplasia phenotype and a high prevalence of autoimmune symptoms, including thrombocytopenia, hemolytic anemia, hypothyroidism and lupus-like nephropathy and vasculopathy. Elevated serum interferon- $\alpha$ activity and a 'type 1 interferon expression signature' was found on whole-transcriptome microarray expression, which could contribute to the autoimmune phenotype in many of these patients [4]. In addition, a significant subset of SPENCD patients has overt neurological abnormalities including developmental delays, spasticity, ataxia, and intracranial calcifications on MRI [5].

Prior to the reports by Briggs et al. [4] and Lausch et al. [5], several other studies had already reported on the variable degree of autoimmune cytopenias and lupus-like symptoms in SPENCD patients, as well as various neurological abnormalities $[9,10]$. Although not a primary focus, the provided height data indicate that the majority of SPENCD patients display significant short stature with a median height around -3 SDS, ranging from -1.8 to -6.5 SD $[4,5]$. A variable but significant degree of short stature, therefore, seems to be an integral part of the SPENCD syndrome.

The presentation of our patients with isolated severe short stature ( -5 SDS) as the cardinal feature in the absence of immune-related or neurodevelopmental symptoms is striking, but not unique: one of the patients described by Briggs et al. [4] also presented with unexplained, isolated short stature and was diagnosed with SPENCD due to an affected brother. They both carried a c. $266 \mathrm{C}>\mathrm{T}$ variant. While she did not demonstrate significant immunological disease (other than the Raynaud phenomenon) or neurological disease, her affected brother, interestingly, suffered from spasticity, elevated antidsDNA and ANA antibodies and a vasculitic skin rash, underlining the poor genotype-phenotype correlation. Both siblings were -3 SDS in height and had platyspondyly on X-rays. A subtle disproportion was present in P1 but not in the younger sibling. Additionally, Briggs et al. [4] reported a patient with the same (p.Ser258Trpfs*39) mutation as identified in our siblings. The reported patient presented with leg pain at the age of 4 years and was also found to have significant short stature ( -3 SDS), although not to the degree as we observed in our patients. Similar to our patients, X-rays showed metaphyseal dysplasia and platyspondyly, but she also had documented 
spasticity, mildly elevated anti-dsDNA $(33$, ref. $<20)$ and ANA (1:640), microglobulinemia, rheumatic fever with hypogammaglobulinemia, increased bone mineral density (+1.5 SDS), and an elevated IGF-1 level (+2.5 SD), none of which our two patients had, again stressing the variability of the phenotype even in patients with the same mutation. In table 2, aggregate patient characteristics of the two major SPENCD studies with reported $A C P 5$ mutations are depicted and compared with our two study patients.

It is important to note that the father and the 11-yearold brother of our patients had moderate short stature as well; however, not nearly as severe as in the two affected siblings. Unfortunately, DNA was unavailable from the father and the brother for exome sequencing. We, therefore, cannot exclude the possibility that an additional genetic variant is partially contributing to the short stature seen in this family. However, as noted above, there are other reported patients with ACP5 deficiency with the same degree of severity of short stature as seen in our patients.

Performing a skeletal survey in cases of idiopathic short stature may be of additional diagnostic benefit as shown by a recent French study [11]. In that study, the authors found an underlying skeletal dysplasia in $20 \%$ of idiopathic short stature cases, most notably so when at least one of the parents had an adult height $<-2$ SD [11]. The etiological diagnosis of SPENCD in these two patients with previously presumed idiopathic short stature has important clinical implications in terms of screening for subclinical comorbid autoimmune or neurological disease, as well as more accurate counseling for future health in both siblings.

In summary, $A C P 5$ mutation should be considered as a rare genetic cause of severe short stature in the setting of typical radiological findings of skeletal metaphyseal dysplasia, even in the absence of overt immunological or neurological disease.

\section{Acknowledgement}

This work was supported by grant No. K23HD07335 to A.D. from the Eunice Kennedy Shriver National Institute of Child Health and Human Development of the National Institutes of Health.

\section{Disclosure Statement}

The authors declare that there are no conflicts of interest.

\section{References}

-1 Guo MH, Shen Y, Walvoord EC, Miller TC, Moon JE, Hirschhorn JN, Dauber A: Whole exome sequencing to identify genetic causes of short stature. Horm Res Paediatr 2014;82: 44-52.

-2 Bundak R, Bas F, Furman A, Gunoz H, Darendeliler F, Saka N, Poyrazoglu S, Neyzi O: Sitting height and sitting height/height ratio references for Turkish children. Eur J Pediatr 2014;173:861-869.

3 de Bruin C, Mericq V, Andrew SF, van Duyvenvoorde HA, Verkaik NS, Losekoot M, Porollo A, Garcia H, Kuang Y, Hanson D, Clayton P, van Gent DC, Wit JM, Hwa V, Dauber A: An XRCC4 splice mutation associated with severe short stature, gonadal failure, and early-onset metabolic syndrome. J Clin Endocrinol Metab 2015;100:E789-E798.

4 Briggs TA, Rice GI, Daly S, Urquhart J, Gornall $\mathrm{H}$, Bader-Meunier B, Baskar K, Baskar S, Baudouin V, Beresford MW, Black GC, Dearman RJ, de Zegher F, Foster ES, Frances C, Hayman AR, Hilton E, Job-Deslandre C, Kulkarni ML, Le Merrer M, Linglart A, Lovell SC, Maurer K, Musset L, Navarro V, Picard C, Puel A, Rieux-Laucat F, Roifman CM, SchollBurgi S, Smith N, Szynkiewicz M, Wiedeman
A, Wouters C, Zeef LA, Casanova JL, Elkon KB, Janckila A, Lebon P, Crow YJ: Tartrateresistant acid phosphatase deficiency causes a bone dysplasia with autoimmunity and a type I interferon expression signature. Nat Genet 2011;43:127-131.

5 Lausch E, Janecke A, Bros M, Trojandt S, Alanay $Y$, De Laet C, Hubner CA, Meinecke P, Nishimura G, Matsuo M, Hirano Y, Tenoutasse S, Kiss A, Rosa RF, Unger SL, Renella R, Bonafe L, Spranger J, Unger S, Zabel B, Superti-Furga A: Genetic deficiency of tartrateresistant acid phosphatase associated with skeletal dysplasia, cerebral calcifications and autoimmunity. Nat Genet 2011;43:132-137.

6 Schorr S, Legum C, Ochshorn M: Spondyloenchondrodysplasia. Enchondromatomosis with severe platyspondyly in two brothers. Radiology 1976;118:133-139.

7 Bune AJ, Hayman AR, Evans MJ, Cox TM: Mice lacking tartrate-resistant acid phosphatase (Acp 5) have disordered macrophage inflammatory responses and reduced clearance of the pathogen, Staphylococcus aureus. Immunology 2001;102:103-113.

-8 Hayman AR, Jones SJ, Boyde A, Foster D, Colledge WH, Carlton MB, Evans MJ, Cox
TM: Mice lacking tartrate-resistant acid phosphatase (Acp 5) have disrupted endochondral ossification and mild osteopetrosis. Development 1996;122:3151-3162.

-9 Renella R, Schaefer E, LeMerrer M, Alanay Y, Kandemir N, Eich G, Costa T, Ballhausen D, Boltshauser E, Bonafe L, Giedion A, Unger S, Superti-Furga A: Spondyloenchondrodysplasia with spasticity, cerebral calcifications, and immune dysregulation: clinical and radiographic delineation of a pleiotropic disorder. Am J Med Genet A 2006;140:541-550.

-10 Navarro V, Scott C, Briggs TA, Barete S, Frances C, Lebon P, Maisonobe T, Rice GI, Wouters $\mathrm{CH}$, Crow YJ: Two further cases of spondyloenchondrodysplasia (SPENCD) with immune dysregulation. Am J Med Genet A 2008; 146A:2810-2815.

11 Flechtner I, Lambot-Juhan K, Teissier R, Colmenares A, Baujat G, Beltrand J, Ajaltouni Z, Pauwels C, Pinto G, Samara-Boustani D, Simon A, Thalassinos C, Le Merrer M, Cormier-Daire V, Polak M: Unexpected high frequency of skeletal dysplasia in idiopathic short stature and small for gestational age patients. Eur J Endocrinol 2014;170:677684. 